\title{
Grafting Polymers onto Carbon Nitride via Visible-Light-Induced Photofunctionalization
}

\author{
Qian Cao, ${ }^{\dagger}$ Baris Kumru, $^{\dagger}$ Markus Antonietti, $^{\dagger}{ }^{\circ}$ and Bernhard V. K. J. Schmidt ${ }^{\dagger,}, *(0)$ \\ ${ }^{\dagger}$ Department of Colloid Chemistry, Max-Planck Institute of Colloids and Interfaces, Am Mühlenberg 1, 14476 Potsdam, Germany \\ ${ }^{\ddagger}$ School of Chemistry, University of Glasgow, Glasgow G12 8QQ U.K.
}

\section{Supporting Information}

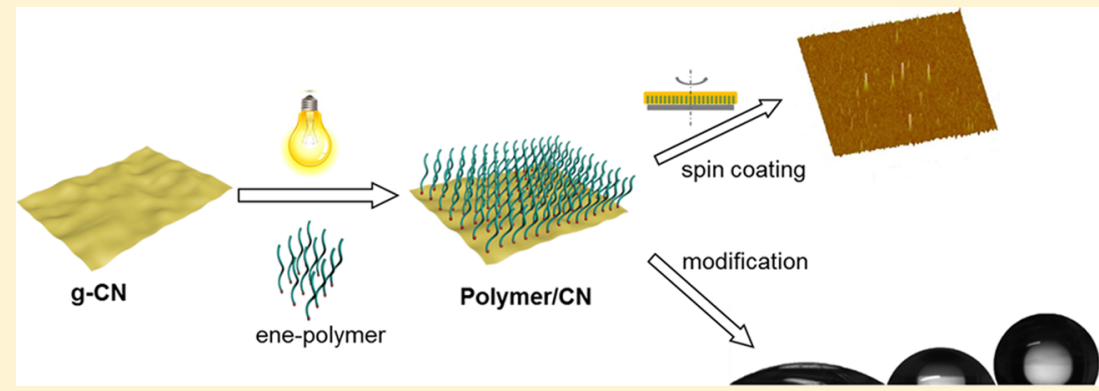

ABSTRACT: Metal-free graphitic carbon nitride $(\mathrm{g}-\mathrm{CN})$ has attracted significant attention recently due to its multiple applications, such as photocatalysis, energy storage and conversion, and biomaterials, albeit formation of $\mathrm{g}$ - $\mathrm{CN}$ films is challenging. Herein, a "grafting to" route to graft polymer brushes onto g-CN via visible-light irradiation is described. Afterward, $\mathrm{g}-\mathrm{CN} /$ polymer films can be obtained through spin coating on glass substrates. As such, the present material provides an improved process toward further application of g-CN in thin films. Moreover, an improved dispersibility in organic solvent was realized after grafting and functional groups (such as epoxides) were introduced to g-CN. Subsequently, the epoxy groups were utilized for further functionalization to adjust the surface polarity.

\section{INTRODUCTION}

Recently, metal-free graphitic carbon nitride ( $\mathrm{g}-\mathrm{CN})$ has been widely investigated, ${ }^{1}$ due to its promising properties for many applications. ${ }^{2,3}$ It consists of repeating tri-s-triazine rings and features a band gap of about $2.7 \mathrm{eV}$ absorbing visible light. Generally studied as a heterogeneous photocatalyst, g-CN can be used in water splitting, ${ }^{4-6} \mathrm{CO}_{2}$ reduction, ${ }^{3,7}$ and pollution photodegradation. $^{8-10}$ The unique optical properties such as photoluminescence $^{11-13}$ and biocompatibility ${ }^{14}$ make g-CN an ideal candidate for bioimaging ${ }^{15,16}$ and biomedical ${ }^{17}$ applications. Recently, two-dimensional g-CN films have been frequently studied ${ }^{18}$ and have broad applications in solar cells, $^{19}$ ionic devices, ${ }^{20}$ and sensing. ${ }^{21}$ In the past, various approaches targeted for the fabrication of g-CN films via chemical vapor deposition (CVD), ${ }^{22}$ thermal vapor condensation, ${ }^{23}$ or magnetron sputtering ${ }^{24}$ were investigated, during which g-CN directly grows from the substrate under suitable conditions, and usually uniform films can be obtained after these processes. For example, $\mathrm{Xu}$ et al. fabricated continuous polymeric $\mathrm{CN}$ thin films for solar cell application, ${ }^{19}$ and Xiao et al. used CVD-fabricated $\mathrm{CN}$ for ion transport. ${ }^{20}$ However, problems such as being costly, complicated processing, and high time requirements are disadvantages of these technologies. Solution processing would be an useful method for film formation, albeit the weak dispersibility of g-CN in most solvents caused by strong van der Waals attractions is the main problem for the solution approach. Hence, it is challenging to employ solution-based common methods, like spin coating 25 or drop casting ${ }^{26}$ to form uniform g-CN films. Moreover, g-CN shows limited selectivity toward $\mathrm{CO}_{2}$ photoreduction because of unfavorable surface properties, which require further modification. ${ }^{27,28}$

In general, several strategies were attempted to improve the physiochemical properties of g-CN, such as doping, ${ }^{29}$ morphology changing, ${ }^{2}$ precursor functionalization, ${ }^{30}$ copolymerization, ${ }^{31}$ and surface grafting. ${ }^{32,33}$ For example, $\mathrm{Xu}$ et al. grafted $n$-bromobutane onto mesoporous $\mathrm{CN}$ for heterogeneous catalysis. ${ }^{34} \mathrm{Bu}$ et al. modified g-CN with hydroxylamine groups by treating with oxygen plasma, thus forming g-CN with excellent hydrophilicity. ${ }^{35}$ Very recently, our group investigated the photoinitiated surface modification of g-CN, e.g., to introduce hydrophilic or hydrophobic moieties. ${ }^{36,37}$ In this process, $\mathrm{g}-\mathrm{CN}$ promoted radical formation under visiblelight irradiation that was utilized to initiate polymerizations ${ }^{38,39}$ or hydrogel formation as well. ${ }^{40,41}$ Among the modification of $\mathrm{g}-\mathrm{CN}$, polymers obtained more and more attraction, due to their versatile properties (e.g., flexibility, easy functionalization, and affordability). ${ }^{42}$ For example, poly(glycidyl methacrylate)

Received: April 30, 2019

Revised: June 6, 2019

Published: June 20, 2019 
Scheme 1. Overview of Atom Transfer Radical Polymerization and Grafting of Polymer Brushes onto g-CN under VisibleLight Irradiation

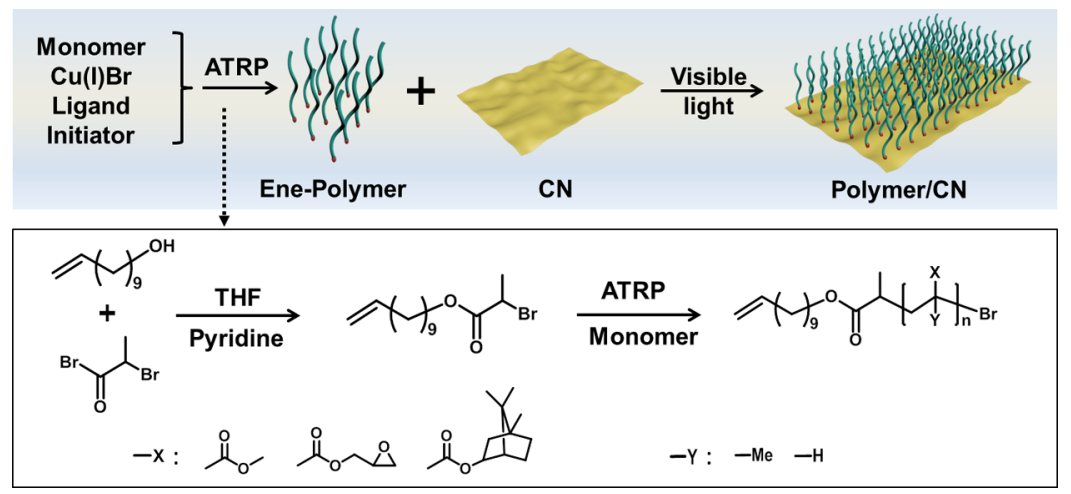

(PGMA) is widely utilized because of the epoxy group that can be easily functionalized in different ways, e.g., Abedul and coworkers employed PGMA as a tunable platform to modify microfluidic devices. ${ }^{43}$ Usually utilized as an economical alternative to polycarbonate, poly(methyl methacrylate) (PMMA) possesses moderate properties of easy handling and processing, while poly(isobornyl acrylate) (PIBA) is commonly applied on microfluidic devices ${ }^{44}$ due to the properties of inertness and transparency. Thus, the surface properties of g-CN might be facilely adjusted by functionalized polymers while preserving its inherent catalytic features.

However, to the best of our knowledge, grafting polymer brushes onto g- $\mathrm{CN}$ has not been reported before, which in turn might lead to an improvement of interface properties of g-CN. Polymer brushes are surface coatings that consist of polymers tethered to a substrate, which can be realized by physisorption or covalent attachment. There are two ways for the covalent attachment, one is "grafting from", where a controlled polymerization $^{45}$ is performed and the polymer chains grow via monomer propagation on the surface. Another approach is grafting to; in this process, an end-functionalized polymer is reacted with a substrate surface. Several factors have an effect on the final grafting density, such as polymer molecular weight, surface coverage, solvent quality, and steric hindrance. ${ }^{46-48}$ Grafting of polymer brushes is commonly used for fabrication of hybrid structures, ${ }^{49}$ where polymers are tethered on a substrate, e.g., inorganic materials such as silicon, gold, hexagonal boron nitride, or silica, ${ }^{50-52}$ so that organicinorganic films can be patterned as well, which can be applied for biotechnology, ${ }^{53}$ microelectronics, ${ }^{54,55}$ microreaction vessels, ${ }^{56}$ and electrical devices. ${ }^{57}$ In this perspective, g-CN as a functional material might be an ideal option for polymer grafting, and a combination of polymer with g-CN might simplify the process for g-CN utilization in various applications.

In the present work, the grafting to method is utilized to graft ene-functional polymers onto g-CN. Ene-functional polymers with different side groups, such as PMMA, PGMA, and PIBA were synthesized by atom transfer radical polymerization (ATRP), and ene-modified initiator 10-undecenyl 2bromopropionate (Un-EBrP) was used during polymerization, as depicted in Scheme 1. The very common and affordable CM (formed from cyanuric acid and melamine as precursors) was utilized as the substrate. Due to the formation of surface radicals under visible light, the CM surface was employed for grafting. The polymer-grafted CM (polymer/CM) was characterized via elemental analysis (EA), thermal gravimetric analysis (TGA), and Fourier transform infrared spectroscopy (FT-IR). Afterward, polymer/CM film materials can be facilely obtained via spin coating and analyzed with an atomic force microscope (AFM) and a scanning electron microscope (SEM). Moreover, PGMA-grafted CM can be utilized to tune the material via further modification. Surface properties after modification was subsequently determined by contact angle and SEM-energy-dispersive X-ray spectroscopy (SEMEDX).

\section{EXPERIMENTAL SECTION}

Materials. Acetic acid (glacial, $\geq 99.9 \%$, Sigma-Aldrich), $\mathrm{Al}_{2} \mathrm{O}_{3}$ basic (Sigma-Aldrich), 2-bromopropionyl bromide (98\%, SigmaAldrich), cyanuric acid (98\%, Sigma-Aldrich), deuterated chloroform $\left(\mathrm{CDCl}_{3}, 99.96 \%\right.$, Sigma-Aldrich), ethanol (absolute, 95\%, SigmaAldrich), ethyl acetate (99.8\%, Sigma-Aldrich), hexane (95\%, SigmaAldrich), melamine (99\%, Sigma-Aldrich), ethyl 2-bromopropionate (EBrP, 98\%, Sigma-Aldrich), pyridine (99.8\%, Sigma-Aldrich), $N, N, N^{\prime}, N^{\prime \prime}, N^{\prime \prime}$-pentamethyldiethylenetriamine (PMDETA, $\geq 98 \%$, Sigma-Aldrich), $1 H, 1 H, 2 H, 2 H$-perfluorodecanethiol (pFDe, $\geq 97 \%$, Sigma-Aldrich), sodium 2-mercaptoethanesulfonate (MESNA, $\geq 98 \%$, Sigma-Aldrich), tetrahydrofuran (THF, $\geq 99.9 \%$, inhibitor-free, Sigma-Aldrich), silica gel (for column chromatography, SigmaAldrich), methanol ( $\geq 99.9 \%$, Sigma-Aldrich), hydrochloric acid ( $\mathrm{HCl}, 37 \%$, Sigma-Aldrich), and 10-undecen-1-ol (98\%, SigmaAldrich) were used as received. Copper(I) bromide $(\mathrm{Cu}(\mathrm{I}) \mathrm{Br}, 98 \%$, Sigma-Aldrich) was purified by stirring in glacial acetic acid overnight, filtered, and washed with absolute ethanol. Isobornyl acrylate (IBA, 98.5\%, Sigma-Aldrich), glycidyl methacrylate (GMA, 97\%, SigmaAldrich), and methyl methacrylate (MMA, 99\%, Sigma-Aldrich) were passed through a basic alumina column prior to use. $50 \mathrm{~W}$ Lightemitting diode (LED) chips (Foxpic High Power 50 W LED Chip Bulb Light DIY White 3800LM $6500 \mathrm{~K}$ ) were connected to a selfmade circuit and cooling system. Sonication was performed in a sonication bath from Elma (Transsonic T310). The initiator 10undecenyl 2-bromopropionate ( $\mathrm{Un}$-EBrP) was synthesized following the work of Matyjaszewski and co-workers, ${ }^{58}$ and the utilized g-CN (CM) was synthesized from the cyanuric acid-melamine complex according to the literature. ${ }^{59}$

ATRP Employing Un-EBrP as an Initiator. General Procedure. $\mathrm{Cu}(\mathrm{I}) \mathrm{Br}$ was added to a $25 \mathrm{~mL}$ round bottom flask in an ice bath, and the flask was sealed with a rubber septum and flushed with argon for $30 \mathrm{~min}$. Subsequently, deoxygenated monomers and deoxygenated PMDETA were added via a syringe. After $\mathrm{Cu}(\mathrm{I}) \mathrm{Br} / \mathrm{PMDETA}$ complex formation, the solution turned light green and the initiator $\mathrm{Un}-\mathrm{EBrP}$ was added via a syringe, the ice bath was removed and the mixture was stirred at the noted temperature and time. Subsequently, the flask was removed from the oil bath and a sample of the raw products was subjected to ${ }^{1} \mathrm{H}$ NMR for calculation of monomer 
Table 1. SEC Results for Ene-Functionalized Polymers Obtained via ATRP

$\begin{array}{cccccc}\text { ene-polymer } & \text { monomer/initiator } & { }^{a} \text { conversion }(\%) & { }^{b} M_{\mathrm{n}, \text { theo }}(\mathrm{kg} / \mathrm{mol}) & { }^{c} M_{\mathrm{n}, \mathrm{SEC}}(\mathrm{kg} / \mathrm{mol}) & 25.9 \\ \text { PGMA } & 200: 1 & 33 & 16 & 21.3 & 1.75 \\ \text { PIBA } & 150: 1 & 96 & 29 & 21.5 & 1.41 \\ \text { PMMA } & 376: 1 & 65 & 24 & { }^{d} D\end{array}$

${ }^{a}$ Calculated via ${ }^{1} \mathrm{H}$ NMR. ${ }^{b}$ Calculated according to the Experimental Section. ${ }^{c}$ Determined via SEC in THF based on PMMA calibration. ${ }^{d} Ð=$ $M_{\mathrm{w}} / M_{\mathrm{n}}$.

conversion. The reaction mixture was diluted in THF and passed through an aluminum oxide column to remove the oxidized catalyst. The polymer was purified by precipitation into methanol, filtered, dried, and finally the polymer was obtained as a white solid. Reference polymerizations with $\mathrm{EBrP}$ were performed in the same way.

Polymerization of MMA. PMMA was obtained according to the general procedure with the following equivalents: MMA (3.76 g, $0.0376 \mathrm{~mol}, 376$ equiv), $\mathrm{Cu}(\mathrm{I}) \mathrm{Br}(7.5 \mathrm{mg}, 0.05 \mathrm{mmol}, 0.5$ equiv), PMDETA ( $8.6 \mathrm{mg}, 0.05 \mathrm{mmol}, 0.5$ equiv), and Un-EBrP (32 mg, 0.1 mmol, 1 equiv). The reaction was carried out at $45{ }^{\circ} \mathrm{C}$ for $30 \mathrm{~min}$ $($ conversion $=65 \%) .\left(M_{\mathrm{n}, \mathrm{SEC}}=21.5 \mathrm{~kg} / \mathrm{mol}, Ð=1.21\right.$. $)$

Polymerization of GMA. PGMA was obtained according to the general procedure with the following equivalents: GMA (5.4 g, 0.04 mol, 200 equiv), $\mathrm{Cu}(\mathrm{I}) \mathrm{Br}(0.15 \mathrm{mg}, 0.1 \mathrm{mmol}, 0.5$ equiv), PMDETA $(17 \mathrm{mg}, 0.1 \mathrm{mmol}, 0.5$ equiv), and Un-EBrP $(64 \mathrm{mg}, 0.2 \mathrm{mmol}, 1$ equiv). The reaction was carried out at $25^{\circ} \mathrm{C}$ for $25 \mathrm{~min}$ (conversion $=33 \%) .\left(M_{\mathrm{n}, \mathrm{SEC}}=25.9 \mathrm{~kg} / \mathrm{mol}, \oplus=1.75\right.$. $)$

Polymerization of IBA. PIBA was obtained according to the general procedure with the following equivalents: IBA (6.23 g, 0.03 mol, 150 equiv), $\mathrm{Cu}(\mathrm{I}) \mathrm{Br}$ ( $30 \mathrm{mg}, 0.2 \mathrm{mmol}, 1$ equiv), PMDETA ( 34 $\mathrm{mg}, 0.2 \mathrm{mmol}, 1$ equiv), and $\mathrm{Un}-\mathrm{EBrP}(64 \mathrm{mg}, 0.2 \mathrm{~mol}, 1$ equiv). The reaction was carried out at $65{ }^{\circ} \mathrm{C}$ for $90 \mathrm{~min}$ (conversion $=96 \%$ ). $\left(M_{\mathrm{n}, \mathrm{SEC}}=21.3 \mathrm{~kg} / \mathrm{mol}, \mathrm{D}=1.41.\right)$

Grafting Polymer Brushes onto g-CN (Polymer/CM). CM (30 $\mathrm{mg}$ ) and $15 \mathrm{~mL}$ of THF were mixed in a round bottom flask and sonicated for $1 \mathrm{~h}$ to yield a CM dispersion. Afterward, $300 \mathrm{mg}$ of the related polymer (PMMA, PGMA, or PIBA) were added to the CM dispersion; the flask was sealed with a rubber septum and flushed with argon for $30 \mathrm{~min}$. The mixture was put between two $50 \mathrm{~W}$ LED daylight sources $(20 \mathrm{~cm}$ distance between light sources) to initiate the grafting. After 2 days, the mixture was washed two times with THF and dried under vacuum.

The control samples were prepared by the same process but treated only with stirring for 2 days without light irradiation.

The study of the CM/PMMA weight ratio was performed with 75 , 150,200 , and $300 \mathrm{mg}$ of PMMA and CM (30 mg), respectively.

Preparation of the Films. Polymer/CM films were prepared via spin coating. At first, $4 \mathrm{mg}$ of the as-prepared PIBA/CM was dispersed in $1 \mathrm{~mL}$ of THF to obtain a PIBA/CM dispersion. Glass slides were used as substrates. The initially stationary glass was flooded with PIBA/CM solution until the entire surface was covered, then accelerated to the desired rotation rate. Acceleration times were $10 \mathrm{~s}$, total spin times were $60 \mathrm{~s}$, and the spin speed was $3000 \mathrm{rpm}$. Afterward, the glass slides were placed under vacuum at ambient temperature for $2 \mathrm{~h}$ to obtain the final dry films.

Modification of PGMA/CM. MESNA-PGMA/CM. In a $15 \mathrm{~mL}$ glass vial, $2 \mathrm{~mL}$ of THF, $5 \mathrm{mg}$ of PGMA/CM, and $50 \mathrm{mg}$ of MESNA were mixed and cooled with an ice bath. Then, $3 \mathrm{mg}$ of LiOH was added slowly, the cooling was removed, and the resulting reaction mixture was stirred at ambient temperature for $3 \mathrm{~h}$. Afterward, the mixture was diluted with $2 \mathrm{~mL}$ of $\mathrm{H}_{2} \mathrm{O}$ three times and centrifuged. The precipitate was dried under vacuum, and finally, $4.5 \mathrm{mg}$ of dry products were obtained.

pFDe-PGMA/CM. In a $15 \mathrm{~mL}$ glass vial, $2 \mathrm{~mL}$ of THF, $7 \mathrm{mg}$ of PGMA/CM, and $300 \mu \mathrm{L}$ of pFDe were mixed and cooled with an ice bath. Then, $3 \mathrm{mg}$ of $\mathrm{LiOH}$ was added slowly, the cooling was removed, and the resulting reaction mixture was stirred at ambient temperature for $1 \mathrm{~h}$. Afterward, the mixture was diluted with $3 \mathrm{~mL}$ of THF three times and centrifuged. The precipitate was dried under vacuum, and finally, $5 \mathrm{mg}$ of dry products were obtained.
As a reference, PMMA/CM was utilized together with $\mathrm{pFDe}$ and MESNA in the same process as with PGMA/CM.

Characterization. Fourier transform infrared (FT-IR) spectra were measured on a Nicolet iS SFT-IR spectrometer. Elemental analysis (EA) for measuring the polymer/CM sample was recorded via a Vario Micro device. Thermogravimetric analysis (TGA) was carried out from ambient temperature to $1000{ }^{\circ} \mathrm{C}$ at a heating rate of $10{ }^{\circ} \mathrm{C} / \mathrm{min}$ using a thermos microbalance TG $209 \mathrm{~F} 1 \mathrm{Libra}$ (Netzsch, Selb, Germany) in an air atmosphere, and data was recorded and analyzed by the Proteus (6.1.0) software package. Proton nuclear magnetic resonance $\left({ }^{1} \mathrm{H}\right.$ NMR) and carbon nuclear magnetic resonance $\left({ }^{13} \mathrm{C} \mathrm{NMR}\right)$ spectra were recorded at ambient temperature on a Bruker Ascend 400. Size exclusion chromatography (SEC) for PGMA, PIBA, and PMMA was conducted in THF with toluene as an internal standard using PSS 1260 -Iso as a pump, a column system of PSS SDV column $\left(8 \times 300 \mathrm{~mm}^{2}\right)$ with a PSS SDV precolumn $(8 \times 50$ $\mathrm{mm}^{2}$ ), PSS-SECcurity-VWD, and PSS-SECcurity-RID as detectors and a calibration with PMMA standards from PSS. The theoretical number-averaged molecular weight was calculated according to the equation $\left(M_{\mathrm{n} \text {,theo }}=[\text { monomer }]_{0} /[\mathrm{I}]_{0} \times\right.$ conversion $\left.\times M_{\text {monomer }}\right)$. Scanning electron microscopy (SEM) was performed using JSM$7500 \mathrm{~F}$ (JEOL) equipped with an Oxford Instruments X-MAX 80 $\mathrm{mm}^{2}$ detector for imaging of the film. The SEM-energy-dispersive Xray spectroscopy (EDX) measurements were conducted by using a JEOL JED-2300 detector in a JEOL JSM-5600 at an accelerating voltage of $15 \mathrm{kV}$. Atomic force microscopy (AFM) was performed with a Nanoscope IIIa Scanning Probe Microscope Controller and NanoWorld Arrow-NCR probes from Digital Instruments. The size of polymer-grafted g-CN was determined by a Zeta Nanosizer instrument (Malvern Instruments, U.K.) at a fixed scattering angle of $90^{\circ}$. All measurements were repeated at least three times. The three-phase contact angle of the polymer-grafted g-CN films was recorded by sessile drop analysis (OCA instrument, Dataphysics ES, Germany); the polymer-grafted g-CN was placed at the bottom of the stage, and about $2 \mu \mathrm{L}$ of water droplet was placed gently on the sample, and three different spots on the film were measured. X-ray diffraction (XRD) patterns of polymer/CM and $\mathrm{CM}$ powders were obtained using a Bruker D8 Advance X-ray diffractometer via $\mathrm{Cu} \mathrm{K} \alpha$ radiation. Solid state ultraviolet-visible (UV-vis) spectra of polymer/CM and CM were recorded via a Cary 500 Scan spectrophotometer equipped with an integrating sphere.

\section{RESULTS AND DISCUSSION}

Synthesis of Ene-Functionalized Polymer. To obtain ene end-functionalized polymers for g-CN modification, a double-bond-functionalized initiator Un-EBrP was prepared following the work of Matyjaszewski and co-workers, ${ }^{58}$ which was used for atom transfer reaction polymerization (ATRP) with $\mathrm{Cu}(\mathrm{I}) \mathrm{Br}$ as the catalyst and PMDETA as the ligand. ${ }^{1} \mathrm{H}$ NMR and ${ }^{13} \mathrm{C}$ NMR (Figure S1) characterized the successful synthesis of Un-EBrP, with signals from the double bond at about $5 \mathrm{ppm}$. Three different monomers, namely MMA, IBA, and GMA, were used in the polymerization. The obtained polymers, PMMA, PIBA, and PGMA were characterized via SEC (Table 1). According to PMMA calibration, $M_{\mathrm{n}, \mathrm{SEC}}$ values of $21.3 \mathrm{~kg} / \mathrm{mol}$ for PIBA, $25.9 \mathrm{~kg} / \mathrm{mol}$ for PGMA, and $21.5 \mathrm{~kg} /$ mol for PMMA were obtained, which indicates the successful polymerization of PGMA, PIBA, and PMMA, with Un-EBrP as 

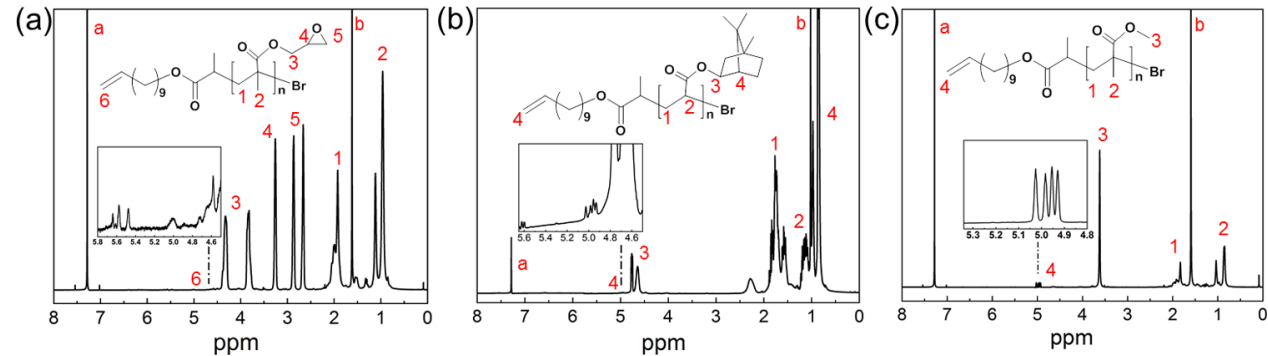

Figure 1. ${ }^{1} \mathrm{H}$ NMR of ene end-functionalized PGMA (a), PIBA (b), and PMMA (c) (peak a corresponds to $\mathrm{CHCl}_{3}$ and peak b to water).

an initiator. Unimodal molecular mass distributions were obtained (Figure S2), yet the ene-functionalized polymers show relatively broad molecular mass distributions with $Đ$ of 1.41 for PIBA, 1.75 for PGMA, and 1.21 for PMMA. The reason might be chain transfer events during the polymerization, although test polymerizations with $\mathrm{EBrP}$ led to similar results (Table S1). In addition, the obtained molecular masses were in reasonable agreement with $M_{n \text {,theo }}$. Moreover, the double-bond incorporation was confirmed via ${ }^{1} \mathrm{H}$ NMR (Figure 1) as the signals from the ene end-group can be found around $5 \mathrm{ppm}$.

Ene-Polymer-Grafted CM. After synthesis of enefunctionalized polymers, grafting of $\mathrm{CM}$ was attempted. CM is readily producing radicals under visible-light irradiation, which can be exploited for photoinitiation. Thus, the double bond at the end of the polymer can be effectively attacked by those radicals and grafting proceeds as expected from the literature-known reactivity of $\mathrm{g}-\mathrm{CN}$ and ene-functional molecules. $^{38,60}$ By these means, functional polymer brushes onto CM were installed. Bulk CM was dispersed in THF and sonicated in advance to increase the accessibility of CM sheet structures (Figure S3a). Afterward, the as-prepared enepolymers PMMA, PIBA, and PGMA were added, respectively. Irradiation with visible lights led to radical formation. Thus, polymers can be introduced to $\mathrm{CM}$ via radical addition, namely PIBA/CM (Figure S3b), PGMA/CM (Figure S3c), and PMMA/CM (Figure S3d). The grafting was followed by FTIR spectroscopy (Figure 2a). Compared to $\mathrm{CM}$ precursor spectra, PIBA/CM, PGMA/CM, and PMMA/CM IR spectra

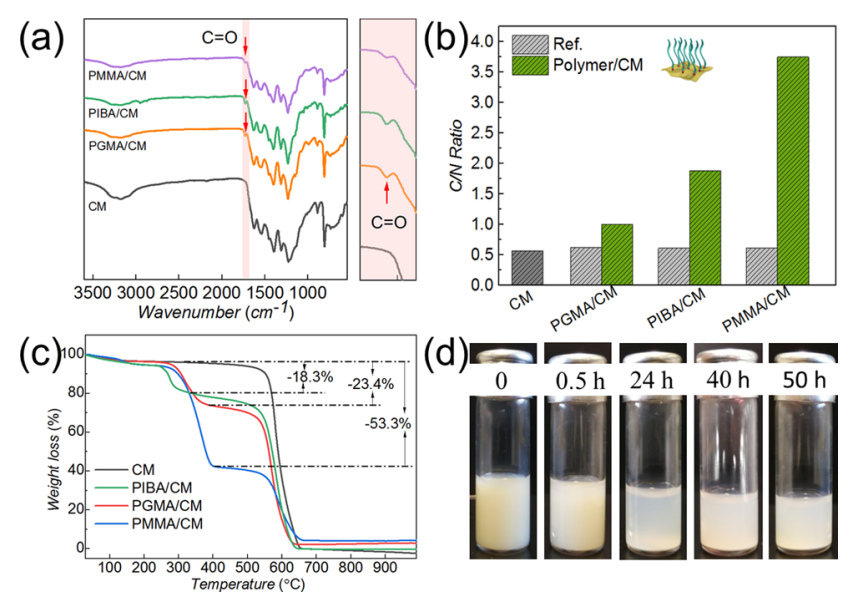

Figure 2. (a) FT-IR spectra of the CM precursor and ene-polymergrafted $\mathrm{CM}$. (b) $\mathrm{C} / \mathrm{N}$ ratio of the $\mathrm{CM}$ precursor and ene-polymergrafted CM obtained via elemental analysis. (c) TGA of the CM precursor and ene-polymer-grafted CM. (d) Photographs of PGMA/ CM dispersed in THF over 2 days. show an additional peak originating from $\mathrm{C}=\mathrm{O}$ stretching at about $1730 \mathrm{~cm}^{-1}$, which corresponds to the carbonyl group in the methacrylic polymers. Moreover, the corresponding enepolymer FT-IR spectra with a direct comparison (Figure S4), indicated the grafting of PIBA, PGMA, and PMMA on CM, respectively. Subsequently, elemental analysis (Figure $2 \mathrm{~b}$ ) results showed a significant increase of the $\mathrm{C} / \mathrm{N}$ ratio compared to the $\mathrm{CM}$ precursor, whereas $\mathrm{CM}$ only had a $\mathrm{C}$ / $\mathrm{N}$ ratio of 0.57 , a change up to 1.88 (PIBA/CM), 1.00 (PGMA/CM), and 3.75 (PMMA/CM) was observed after grafting (Table S2), demonstrating successful ene-polymer grafting. Notably, only minor changes were observed for the reference samples, which were prepared via the same process without light irradiation, i.e., $\mathrm{C} / \mathrm{N}$ ratios of 0.61 (ref PIBA/ CM), 0.71 (ref PGMA/CM), and 0.61 (ref PMMA/CM) were observed. Hence, it can be confirmed that only slight physical attachment was present during mixing of polymers and CM, while a chemical bond was formed under visible-light irradiation.

The amount of grafted polymers differs for the respective polymers, and thus thermogravimetric analysis (TGA, Figure 2c) was performed. The weight loss of polymers was analyzed during heating: $18.3 \%$ weight loss of PIBA/CM on heating at $220-300{ }^{\circ} \mathrm{C}, 23.4 \%$ loss of weight of PGMA/CM on heating at $250-380{ }^{\circ} \mathrm{C}$, and $53.3 \%$ loss of weight of PMMA/CM on heating at $260-400{ }^{\circ} \mathrm{C}$, respectively. Afterward, the amount of grafted ene-polymer grafting was calculated ${ }^{61}$ as shown specifically in Table S3. Therefore, a CM unit is defined consisting of seven nitrogen atoms and six carbon atoms. According to this calculation, PIBA- and PGMA-grafted CM show almost the same grafting density of 1 polymer chain grafted per $526 \mathrm{CM}$ units $\left(1.11 \times 10^{-2} \mathrm{mmol} / \mathrm{g}\right)$ and $500 \mathrm{CM}$ units $\left(1.18 \times 10^{-2} \mathrm{mmol} / \mathrm{g}\right)$, respectively. On the other hand, PMMA/CM shows a significantly higher grafting density of $4.46 \times 10^{-2} \mathrm{mmol} / \mathrm{g}$, meaning 1 PMMA chain per 132 units of CM. Demonstrating that even with almost the same molecular weight, a difference of the grafting density from different polymers is obtained. In the literature, it was stated that the cross-sectional area of a polymer chain with a similar $M_{\mathrm{n}}$ and in good solvent is around $170 \AA^{2}{ }^{62}$ which might be larger than the spaces between active species on the g-CN surface. Hence, only a limited amount of active radicals are utilized in the grafting to process. Moreover, steric hindrance differs according to the polymer sidechains, as PGMA with an epoxide group and PIBA with a cycloalkyl group cause larger steric hindrance than PMMA (only with methyl and methylcarboxylate groups), which also might result in higher PMMA grafting density.

To further elucidate the grafting process, utilization of different mass ratios of CM to PMMA was attempted (Figures S5 and S6). With a certain amount of CM (30 mg), simply 
adjusting the PMMA from 75 to $300 \mathrm{mg}$, an increased weight loss of PMMA with thermal treatment and increased $\mathrm{C} / \mathrm{N}$ ratio from elemental analysis were found. Thus, it is indicated that with the introduction of increased amounts of PMMA, increased numbers of surface active species were utilized for grafting. In such a way, it can be concluded that the active sites on the surface are not saturated employing the initial ratios of PMMA and CM. Moreover, XRD (Figure S7a) and ultraviolet absorption spectrum (Figure S7b) show no significant changes compared to CM after grafting, which indicated that the inherent structural and absorption properties of CM were still preserved enabling further applications of the grafted materials.

Dispersibility and Film Fabrication. Commonly, g-CN has poor dispersibility, which limits its application, for example in solvent processing. Thus, further deposition is restricted, e.g., spin coating results in complicated processing for further applications as film materials, e.g., solar cells, fuel cells and organic light-emitting diodes. Therefore, the dispersibility of ene-polymer-grafted $\mathrm{CM}$ in organic media was investigated. As an example, PIBA/CM was dispersed in THF (Figures $2 \mathrm{~d}$ and S8) over 2 days and chloroform (Figure S9) over $20 \mathrm{~h}$, respectively, and only minor sedimentation was found. In comparison, the CM precursor does not form a stable dispersion at all, which confirms an improved stability of polymer/CM dispersions in organic solvent. Furthermore, dynamic light scattering (Table S4) in THF shows a significant decrease of CM hydrodynamic diameters after grafting, because $\mathrm{CM}$ is a sheetlike structure, and during the visiblelight-inducing process, repelling force, and steric hindrance between two polymer chains causing the exfoliation of the CM layer structure, thus resulting in a smaller size after grafting.

Subsequently, the polymer-brush-grafted CM was utilized to form films via the solution-based deposition method of spin coating, e.g., a PIBA/CM film on a glass substrate was demonstrated (Figure 3a). A transparent film was obtained and

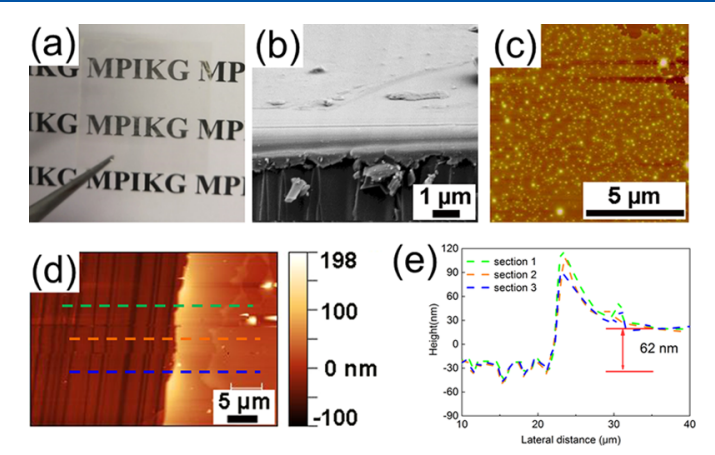

Figure 3. (a) Digital picture of the PIBA/CM film after spin coating on a glass substrate. (b) SEM image of the PIBA/CM film after spin coating. (c)-(e) show the AFM profile of spin-coated PIBA/CM film, thickness, and thickness distribution with three lines in detail, respectively.

compared to opaque CM films (Figure S10a), without an obvious change of the UV-vis absorption (Figure S11). The structure of the PIBA/CM film was characterized by scanning electron microscopy (SEM) and atomic force microscopy (AFM) images (Figure 3b,c), and a smooth thin film structure was confirmed, with a surface roughness of $1.49 \mathrm{~nm}$ (Figure S12). Besides, with the same condition for spin coating of CM precursors, no clear film structure was found via AFM investigation (Figure $\mathrm{S} 10 \mathrm{~b}, \mathrm{c}$ ). On the one hand, improved

dispersibility in organic solvent promoted better film formation. On the other hand, PIBA possesses excellent adhesion $^{63}$ and film-forming properties, which has been recognized as a commercial coating material, ${ }^{64}$ as accelerated film formation contributes to a better film structure. The thickness of the PIBA/CM film was characterized via section analysis (Figure 3d,e). The corresponding micrograph indicates a thickness of the PIBA/CM film of approximately $62 \mathrm{~nm}$, and the thickness of the CM film (Figure S13) was approximately $20 \mathrm{~nm}$. Thus, the difference in thickness between PIBA/CM and CM might be the thickness of polymer brushes as a rough assumption. Moreover, PIBA can be used as a polymer dielectric, and such thickness of thin films is appropriate for the electric gate function. ${ }^{65}$ As mentioned before, the structural and absorption properties of CM were still preserved after grafting. Hence, an improved process toward g-CN utilization as an energy conversion device, solar cell, and other film materials is provided.

PGMA/CM Surface Modification. In addition to the facile formation of thin films via spin coating, the functional groups such as epoxides in PGMA can be utilized for further modification. Hence, the surface properties of PGMA/CM brush materials can be readily adjusted. As a proof of concept, the thiol-epoxy addition reaction of PGMA/CM with sodium 2-mercaptoethanesulfonate (MESNA) and perfluorodecanethiol (pFDe) was attempted, respectively. The functionalization was carried out following the work of De and Khan, ${ }^{66}$ using $\mathrm{LiOH}$ as a catalyst at ambient temperature and reaction for 3 and $1 \mathrm{~h}$, respectively (Figure $4 \mathrm{a}$ ). The obtained

(a)

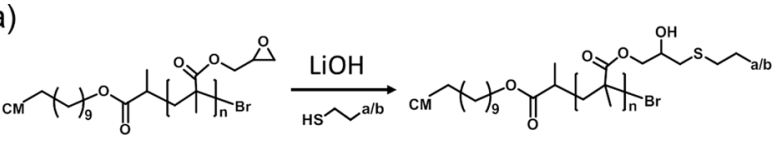

(b)
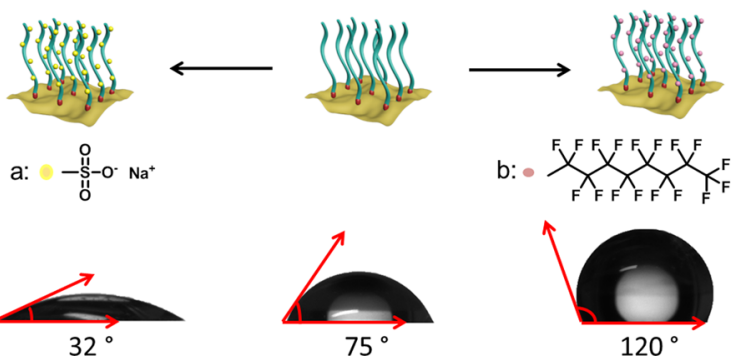

(c)

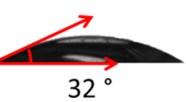

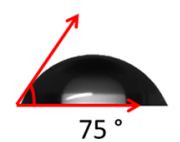

Figure 4. (a) Modification of PGMA/CM via thiol-addition-mediated epoxy ring-opening. (b) Illustration of PGMA/CM modified with sodium 2-mercaptoethanesulfonate (a, MESNA) and $1 \mathrm{H}, 1 \mathrm{H}, 2 \mathrm{H}, 2 \mathrm{H}$ perfluorodecanethiol (b, pFDe), respectively. (c) Contact angle of MESNA-PGMA/CM, PGMA/CM, and pFDe-PGMA/CM from left to right, respectively.

MESNA-PGMA/CM and pFDe-PGMA/CM materials were characterized via several methods, e.g., FT-IR (Figure S14a). For example, compared to reference experiments with PMMA/CM (Figure S14b), C-F stretch and $\mathrm{S}=\mathrm{O}$ stretch bands were found from the related FT-IR spectra, respectively. As MESNA is more hydrophilic and pFDe is more hydrophobic, PGMA/CM films (Figures S15 and S16) with opposite polarity were obtained (Figure $4 \mathrm{~b}$ ). The surface properties were characterized via contact angle measurements (Figures $4 \mathrm{c}$ and S17). MESNA-PGMA/CM was highly hydrophilic (contact angle $32^{\circ}$ ), and pFDe-PGMA/CM showed a highly hydrophobic property (contact angle $120^{\circ}$ ), whereas PGMA/ 
CM showed a relatively hydrophilic property with a contact angle of $75^{\circ}$ as expected. Further investigation was performed by SEM (Figure S18a,b), which showed no change in morphology after modification. Moreover, energy-dispersive X-ray (EDX) (Figure S18c,d) indicated the appearance of C, $\mathrm{N}, \mathrm{O}, \mathrm{Na}$, and $\mathrm{S}$ throughout the surface of MESNA-PGMA/ $\mathrm{CM}$ and $\mathrm{C}, \mathrm{N}, \mathrm{O}, \mathrm{F}$, and $\mathrm{S}$ throughout the surface of pFDePGMA/CM, indicating successful functionalization.

\section{CONCLUSIONS}

In conclusion, a grafting to method was utilized to realize the grafting of defined polymers on g-CN. Thus, polymer/g-CN hybrid materials were fabricated. Functional polymers were prepared via ATRP from an initiator with ene functionality, and visible light was used to perform photoinduced grafting. Thus, functional polymers namely PIBA, PGMA, and PMMA were grafted onto g-CN. However, varied grafting density was observed for the different polymers probably due to different steric hindrance. The as-prepared polymer/g-CN has improved dispersibility in organic solvent, which simplifies the further processing toward film fabrication. Compared to CM, PIBA/ $\mathrm{CM}$ films on a glass substrate were facilely obtained via the spin coating deposition method. Film thicknesses in the range of $60 \mathrm{~nm}$ and surface roughness around $1.49 \mathrm{~nm}$ were observed, with a relatively smooth surface and ideal thickness toward further application as film materials. Moreover, the epoxide group of PGMA/CM was utilized for further modification. Thus, the surface properties of PGMA/CM brush materials were readily adjusted to be either hydrophilic or hydrophobic according to the attached species. Overall, polymer-grafted g-CN provides a novel way for combination of polymers with $\mathrm{g}-\mathrm{CN}$. On one hand, improvement of the process toward g-CN utilization in film materials was achieved, as such materials might be of interest for solar cells, electric devices, or photocatalysis. On the other hand, g-CN-containing films with adjustable hydrophobicity were provided, which might be a promising material for photocatalysis with improved selectivity.

\section{ASSOCIATED CONTENT}

\section{S Supporting Information}

The Supporting Information is available free of charge on the ACS Publications website at DOI: 10.1021/acs.macromol.9b00894.

Additional synthetic procedures; calculation; FT-IR; AFM; XRD; UV-vis; and DLS (PDF)

\section{AUTHOR INFORMATION}

\section{Corresponding Author}

*E-mail bernhard.schmidt@mpikg.mpg.de. Tel (+49) 331567 9509. Fax (+49) 3315679502.

\section{ORCID $\odot$}

Markus Antonietti: 0000-0002-8395-7558

Bernhard V. K. J. Schmidt: 0000-0002-3580-7053

Notes

The authors declare no competing financial interest.

\section{ACKNOWLEDGMENTS}

The authors are grateful for funding from the Max-Planck Society. The authors acknowledge Marlies Graewert for SEC measurements, Ang Li for assistance with illustrations, Antje
Voelkel for elemental analysis and TGA investigation, Reinhild Dünnebacke for AFM investigation, Tobias Heil for assisting with SEM and EDX measurements, and Irina Shekova and Jianrui Zhang for assistance with contact angle measurements.

\section{REFERENCES}

(1) Oh, J.; Lee, J. M.; Yoo, Y.; Kim, J.; Hwang, S.-J.; Park, S. New insight of the photocatalytic behaviors of graphitic carbon nitrides for hydrogen evolution and their associations with grain size, porosity, and photophysical properties. Appl. Catal., B 2017, 218, 349-358.

(2) Yan, H. Soft-templating synthesis of mesoporous graphitic carbon nitride with enhanced photocatalytic $\mathrm{H}_{2}$ evolution under visible light. Chem. Commun. 2012, 48, 3430-3432.

(3) Wang, K.; Li, Q.; Liu, B.; Cheng, B.; Ho, W.; Yu, J. Sulfur-doped g- $\mathrm{C}_{3} \mathrm{~N}_{4}$ with enhanced photocatalytic $\mathrm{CO}_{2}$-reduction performance. Appl. Catal., B 2015, 176-177, 44-52.

(4) Martin, D. J.; Qiu, K.; Shevlin, S. A.; Handoko, A. D.; Chen, X.; Guo, Z.; Tang, J. Highly efficient photocatalytic $\mathrm{H}_{2}$ evolution from water using visible light and structure-controlled graphitic carbon nitride. Angew. Chem., Int. Ed. 2014, 53, 9240-9245.

(5) Zheng, Y.; Jiao, Y.; Zhu, Y.; Li, L. H.; Han, Y.; Chen, Y.; Du, A.; Jaroniec, M.; Qiao, S. Z. Hydrogen evolution by a metal-free electrocatalyst. Nat. Commun. 2014, 5, No. 3783.

(6) Wang, X.; Maeda, K.; Thomas, A.; Takanabe, K.; Xin, G.; Carlsson, J. M.; Domen, K.; Antonietti, M. A metal-free polymeric photocatalyst for hydrogen production from water under visible light. Nat. Mater. 2009, 8, 76-80.

(7) Huang, Y.; Wang, Y.; Bi, Y.; Jin, J.; Ehsan, M. F.; Fu, M.; He, T. Preparation of $2 \mathrm{D}$ hydroxyl-rich carbon nitride nanosheets for photocatalytic reduction of $\mathrm{CO}_{2}$. RSC Adv. 2015, 5, 33254-33261.

(8) Ma, J.; Wang, C.; He, H. Enhanced photocatalytic oxidation of $\mathrm{NO}$ over $\mathrm{g}_{-} \mathrm{C}_{3} \mathrm{~N}_{4}-\mathrm{TiO}_{2}$ under UV and visible light. Appl. Catal., B 2016, 184, 28-34.

(9) Sano, T.; Tsutsui, S.; Koike, K.; Hirakawa, T.; Teramoto, Y.; Negishi, N.; Takeuchi, K. Activation of graphitic carbon nitride (g$\mathrm{C}_{3} \mathrm{~N}_{4}$ ) by alkaline hydrothermal treatment for photocatalytic NO oxidation in gas phase. J. Mater. Chem. A 2013, 1, 6489-6496.

(10) Sun, J.; Schmidt, B. V.; Wang, X.; Shalom, M. Self-standing carbon nitride-based hydrogels with high photocatalytic activity. ACS Appl. Mater. Interfaces 2017, 9, 2029-2034.

(11) Cui, Q.; Xu, J.; Wang, X.; Li, L.; Antonietti, M.; Shalom, M. Phenyl-modified carbon nitride quantum dots with distinct photoluminescence behavior. Angew. Chem., Int. Ed. 2016, 55, 3672-3676.

(12) Shen, J.; Zhu, Y.; Yang, X.; Li, C. Graphene quantum dots: emergent nanolights for bioimaging, sensors, catalysis and photovoltaic devices. Chem. Commun. 2012, 48, 3686-3699.

(13) Son, E. J.; Lee, S. H.; Kuk, S. K.; Pesic, M.; Choi, D. S.; Ko, J. W.; Kim, K.; Hollmann, F.; Park, C. B. Carbon nanotub-graphitic carbon nitride hybrid films for flavoenzyme-catalyzed photoelectrochemical cells. Adv. Funct. Mater. 2018, 28, No. 1705232.

(14) Cao, Q.; Cui, Q.; Yang, Y.; Xu, J.; Han, C.; Li, L. Graphitic carbon nitride as a distinct solid stabilizer for emulsion polymerization. Chem. - Eur. J. 2018, 24, 2286-2291.

(15) Lu, Y.-C.; Chen, J.; Wang, A.-J.; Bao, N.; Feng, J.-J.; Wang, W.; Shao, L. Facile synthesis of oxygen and sulfur co-doped graphitic carbon nitride fluorescent quantum dots and their application for mercury (II) detection and bioimaging. J. Mater. Chem. C 2015, 3, $73-78$.

(16) Kim, J. K.; Park, S.; Yoo, R. J.; Jeong, H. J.; Oh, J.; Lee, Y. J.; Park, S.; Kim, D. W. Thin PEGylated carbon nitrides: waterdispersible organic nanodots as bioimaging probes. Chem. - Eur. J. 2018, 24, 3506-3511.

(17) Dearnaley, G.; Arps, J. H. Biomedical applications of diamondlike carbon (DLC) coatings: A review. Surf. Coat. Technol. 2005, 200, $2518-2524$.

(18) Hu, Y.; Shim, Y.; Oh, J.; Park, S.; Park, S.; Ishii, Y. Synthesis of 13C-,15N-labeled graphitic carbon nitrides and NMR-based evidence 
of hydrogen-bonding assisted two-dimensional assembly. Chem. Mater. 2017, 29, 5080-5089.

(19) Xu, J.; Brenner, T. J. K.; Chabanne, L.; Neher, D.; Antonietti, M.; Shalom, M. Liquid-based growth of polymeric carbon nitride layers and their use in a mesostructured polymer solar cell with Voc exceeding 1 V. J. Am. Chem. Soc. 2014, 136, 13486-13489.

(20) Xiao, K.; Giusto, P.; Wen, L.; Jiang, L.; Antonietti, M. Nanofluidic ion transport and energy conversion through ultrathin free-standing polymeric carbon nitride membranes. Angew. Chem. 2018, 130, 10280-10283.

(21) Wang, Q.; Wang, W.; Lei, J.; Xu, N.; Gao, F.; Ju, H. Fluorescence quenching of carbon nitride nanosheet through its interaction with DNA for versatile fluorescence sensing. Anal. Chem. 2013, 85, 12182-12188.

(22) Zhang, Y.; Zhou, Z.; Li, H. Crystalline carbon nitride films formation by chemical vapor deposition. Appl. Phys. Lett. 1996, 68, 634-636.

(23) Bian, J.; Li, J.; Kalytchuk, S.; Wang, Y.; Li, Q.; Lau, T. C.; Niehaus, T. A.; Rogach, A. L.; Zhang, R.-Q. Efficient emission facilitated by multiple energy level transitions in uniform graphitic carbon nitride films deposited by thermal vapor condensation. ChemPhysChem 2015, 16, 954-959.

(24) Lejeune, M.; Durand-Drouhin, O.; Zellama, K.; Benlahsen, M. Structure and optical properties of carbon nitride films deposited by magnetron sputtering. Solid State Commun. 2001, 120, 337-342.

(25) Safaei, J.; Mohamed, N. A.; Noh, M. F. M.; Soh, M. F.; Riza, M. A.; Mustakim, N. S. M.; Ludin, N. A.; Ibrahim, M. A.; Isahak, W. N. R. W.; Teridi, M. A. M. Facile fabrication of graphitic carbon nitride (g$\mathrm{C}_{3} \mathrm{~N}_{4}$ ) thin film. J. Alloys Compd. 2018, 769, 130-135.

(26) Ge, L.; Han, C. Synthesis of MWNTs $/ g-C_{3} \mathrm{~N}_{4}$ composite photocatalysts with efficient visible light photocatalytic hydrogen evolution activity. Appl. Catal., B 2012, 117-118, 268-274.

(27) Raciti, D.; Mao, M.; Park, J. H.; Wang, C. Mass transfer effects in $\mathrm{CO}_{2}$ reduction on $\mathrm{Cu}$ nanowire electrocatalysts. Catal. Sci. Technol. 2018, 8, 2364-2369.

(28) Li, A.; Wang, T.; Li, C.; Huang, Z.; Luo, Z.; Gong, J. Adjusting the reduction potential of electrons by quantum confinement for selective photoreduction of $\mathrm{CO}_{2}$ to methanol. Angew. Chem. 2019, 131, 3844-3848.

(29) Zhang, Y.; Mori, T.; Niu, L.; Ye, J. Non-covalent doping of graphitic carbon nitride polymer with graphene: controlled electronic structure and enhanced optoelectronic conversion. Energy Environ. Sci. 2011, 4, 4517-4521.

(30) Zhang, J.; Zhang, G.; Chen, X.; Lin, S.; Möhlmann, L.; Dołęga, G.; Lipner, G.; Antonietti, M.; Blechert, S.; Wang, X. Co-monomer control of carbon nitride semiconductors to optimize hydrogen evolution with visible light. Angew. Chem., Int. Ed. 2012, 51, 31833187.

(31) Zhang, J.; Chen, X.; Takanabe, K.; Maeda, K.; Domen, K.; Epping, J. D.; Fu, X.; Antonietti, M.; Wang, X. Synthesis of a carbon nitride structure for visible-light catalysis by copolymerization. Angew. Chem., Int. Ed. 2010, 49, 441-444.

(32) Zhang, P.; Li, H.; Wang, Y. Post-functionalization of graphitic carbon nitrides by grafting organic molecules: toward $\mathrm{C}-\mathrm{H}$ bond oxidation using atmospheric oxygen. Chem. Commun. 2014, 50, 6312-6315.

(33) Sun, J.; Phatake, R.; Azoulay, A.; Peng, G.; Han, C.; Barrio, J.; $\mathrm{Xu}$, J.; Wang, X.; Shalom, M. Covalent functionalization of carbon nitride frameworks through cross-coupling reactions. Chem. - Eur. J. 2018, 24, 14921-14927.

(34) Xu, J.; Wu, F.; Jiang, Q.; Li, Y.-X. Mesoporous carbon nitride grafted with n-bromobutane: a high-performance heterogeneous catalyst for the solvent-free cycloaddition of $\mathrm{CO}_{2}$ to propylene carbonate. Catal. Sci. Technol. 2015, 5, 447-454.

(35) Bu, X.; Li, J.; Yang, S.; Sun, J.; Deng, Y.; Yang, Y.; Wang, G.; Peng, Z.; He, P.; Wang, X.; et al. Surface modification of $\mathrm{C}_{3} \mathrm{~N}_{4}$ through oxygen-plasma treatment: a simple way toward excellent hydrophilicity. ACS Appl. Mater. Interfaces 2016, 8, 31419-31425.
(36) Kumru, B.; Antonietti, M.; Schmidt, B. V. K. J. Enhanced dispersibility of graphitic carbon nitride particles in aqueous and organic media via a one-pot grafting approach. Langmuir 2017, 33, 9897-9906.

(37) Kumru, B.; Cruz, D.; Heil, T.; Schmidt, B. V. K. J.; Antonietti, $M$. Electrostatic stabilization of carbon nitride colloids in organic solvents enables stable dispersions and transparent homogeneous $\mathrm{CN}$ films for optoelectronics. J. Am. Chem. Soc. 2018, 140, 17532-17537.

(38) Fu, Q.; Ruan, Q.; McKenzie, T. G.; Reyhani, A.; Tang, J.; Qiao, G. G. Development of a robust PET-RAFT polymerization using graphitic carbon nitride $\left(\mathrm{g}-\mathrm{C}_{3} \mathrm{~N}_{4}\right)$. Macromolecules 2017, 50, 75097516.

(39) Dadashi-Silab, S.; Tasdelen, M. A.; Kiskan, B.; Wang, X.; Antonietti, M.; Yagci, Y. Photochemically mediated atom transfer radical polymerization using polymeric semiconductor mesoporous graphitic carbon nitride. Macromol. Chem. Phys. 2014, 215, 675-681.

(40) Kumru, B.; Shalom, M.; Antonietti, M.; Schmidt, B. V. K. J. Reinforced hydrogels via carbon nitride initiated polymerization. Macromolecules 2017, 50, 1862-1869.

(41) Kumru, B.; Molinari, V.; Dunnebacke, R.; Blank, K. G.; Schmidt, B. V. K. J. Extremely compressible hydrogel via incorporation of modified graphitic carbon nitride. Macromol. Rapid Commun. 2019, 40, No. 1800712.

(42) Kumru, B.; Barrio, J.; Zhang, J.; Antonietti, M.; Shalom, M.; Schmidt, B. V. K. J. Robust carbon nitride-based thermoset coatings for surface modification and photochemistry. ACS Appl. Mater. Interfaces 2019, 11, 9462-9469.

(43) Álvarez-Martos, I.; Alonso-Bartolomé, R.; Mulas Hernández, V.; Anillo, A.; Costa-García, A.; García Alonso, F. J.; FernándezAbedul, M. T. Poly(glycidyl methacrylate) as a tunable platform of modifiers for microfluidic devices. React. Funct. Polym. 2016, 100, 8996.

(44) López-García, M. d. C.; Beebe, D. J.; Crone, W. C. Characterization of poly (isobornyl acrylate) as a construction material for microfluidic applications. J. Appl. Polym. Sci. 2007, 105, 1894-1902.

(45) Ejaz, M.; Yamamoto, S.; Ohno, K.; Tsujii, Y.; Fukuda, T. Controlled graft polymerization of methyl methacrylate on silicon substrate by the combined use of the langmuir-blodgett and atom transfer radical polymerization techniques. Macromolecules 1998, 31, 5934-5936.

(46) Devaux, C.; Cousin, F.; Beyou, E.; Chapel, J. P. Low swelling capacity of highly stretched polystyrene brushes. Macromolecules 2005, 38, 4296-4300.

(47) Liao, W.-P.; Elliott, I. G.; Faller, R.; Kuhl, T. L. Normal and shear interactions between high grafting density polymer brushes grown by atom transfer radical polymerization. Soft Matter 2013, 9, $5753-5761$

(48) Goujon, F.; Malfreyt, P.; Tildesley, D. J. The compression of polymer brushes under shear: the friction coefficient as a function of compression, shear rate and the properties of the solvent. Mol. Phys. 2005, 103, 2675-2285.

(49) Senaratne, W.; Andruzzi, L.; Ober, C. K. Self-assembled monolayers and polymer brushes in biotechnology: current applications and future perspectives. Biomacromolecules 2005, 6, $2427-2448$.

(50) Ostaci, R.-V.; Damiron, D.; Capponi, S.; Vignaud, G.; Léger, L.; Grohens, Y.; Drockenmuller, E. Polymer brushes grafted to "passivated" silicon substrates using click chemistry. Langmuir 2008, 24, 2732-2739.

(51) Tokareva, I.; Minko, S.; Fendler, J. H.; Hutter, E. Nanosensors based on responsive polymer brushes and gold nanoparticle enhanced transmission surface plasmon resonance spectroscopy. J. Am. Chem. Soc. 2004, 126, 15950-15951.

(52) Sheng, W.; Amin, I.; Neumann, C.; Dong, R.; Zhang, T.; Wegener, E.; Chen, W. L.; Forster, P.; Tran, H. Q.; Loffler, M.; Winter, A.; Rodriguez, R. D.; Zschech, E.; Ober, C. K.; Feng, X.; Turchanin, A.; Jordan, R. Polymer Brushes on Hexagonal Boron Nitride. Small 2019, 15, No. 1805228. 
(53) Rodriguez-Emmenegger, C.; Preuss, C. M.; Yameen, B.; PopGeorgievski, O.; Bachmann, M.; Mueller, J. O.; Bruns, M.; Goldmann, A. S.; Bastmeyer, M.; Barner-Kowollik, C. Controlled cell adhesion on poly(dopamine) interfaces photopatterned with non-fouling brushes. Adv. Mater. 2013, 25, 6123-6127.

(54) Ionov, L.; Bocharova, V.; Diez, S. Biotemplated synthesis of stimuli-responsive nanopatterned polymer brushes on microtubules. Soft Matter 2009, 5, 67-71.

(55) Tu, H.; Heitzman, C. E.; Braun, P. V. Patterned poly (Nisopropylacrylamide) brushes on silica surfaces by microcontact printing followed by surface-initiated polymerization. Langmuir 2004, 20, 8313-8320.

(56) Costantini, F.; Bula, W. P.; Salvio, R.; Huskens, J.; Gardeniers, H. J. G. E.; Reinhoudt, D. N.; Verboom, W. Nanostructure based on polymer brushes for efficient heterogeneous catalysis in microreactors. J. Am. Chem. Soc. 2009, 131, 1650-1651.

(57) Ouyang, H.; Xia, Z.; Zhe, J. Static and dynamic responses of polyelectrolyte brushes under external electric field. Nanotechnology 2009, 20, No. 195703.

(58) Matyjaszewski, K.; Miller, P. J.; Shukla, N.; Immaraporn, B.; Gelman, A.; Luokala, B. B.; Siclovan, T. M.; Kickelbick, G.; Vallant, T.; Hoffmann, H.; Pakula, T. Polymers at interfaces: using atom transfer radical polymerization in the controlled growth of homopolymers and block copolymers from silicon surfaces in the absence of untethered sacrificial initiator. Macromolecules 1999, 32, $8716-8724$.

(59) Shalom, M.; Inal, S.; Fettkenhauer, C.; Neher, D.; Antonietti, M. Improving carbon nitride photocatalysis by supramolecular preorganization of monomers. J. Am. Chem. Soc. 2013, 135, 71187121.

(60) Mazzolini, J.; Boyron, O.; Monteil, V.; Gigmes, D.; Bertin, D.; D'Agosto, F.; Boisson, C. Polyethylene end functionalization using radical-mediated thiol-ene chemistry: use of polyethylenes containing alkene end functionality. Macromolecules 2011, 44, 3381-3387.

(61) Zeininger, L.; Portilla, L.; Halik, M.; Hirsch, A. Quantitative determination and comparison of the surface binding of phosphonic acid, carboxylic acid, and catechol ligands on $\mathrm{TiO}_{2}$ nanoparticles. Chem. - Eur. J. 2016, 22, 13506-13512.

(62) Jones, D. M.; Brown, A. A.; Huck, W. T. J. L. Surface-initiated polymerizations in aqueous media: effect of initiator density. Langmuir 2002, 18, 1265-1269.

(63) Inui, T.; Sato, E.; Matsumoto, A. Pressure-sensitive adhesion system using acrylate block copolymers in response to photoirradiation and postbaking as the dual external stimuli for on-demand dismantling. ACS Appl. Mater. Interfaces 2012, 4, 2124-2132.

(64) Shaw, D. G.; Dawson, E.; Cline, D.; Langlois, M. Acrylate coating material. Google Patent US5440446, 1995.

(65) Seong, H.; Pak, K.; Joo, M.; Choi, J.; Im, S. G. Vapor-phase deposited ultrathin polymer gate dielectrics for high-performance organic thin film transistors. Adv. Electron. Mater. 2016, 2, No. 1500209.

(66) De, S.; Khan, A. Efficient synthesis of multifunctional polymers via thiol-epoxy "click" chemistry. Chem. Commun. 2012, 48, 31303132 . 